\title{
BONANÇA ECONÔMICA, DESENVOLVIMENTO LATINO-AMERICANO E O CASO DO CHILE ${ }^{(*)}$
}

\author{
ECONOMIC BONANZA, LATIN AMERICA \\ DEVELOPMENT AND THE CASE OF CHILE
}

Juliane Caravieri Martins Gamba ${ }^{(*)}$

Resumo: A industrialização substitutiva de importações (ISI) foi preconizada pelo pensamento da CEPAL, principalmente dos anos 50, como estratégia de desenvolvimento econômico para os países latino-americanos romperem com o subdesenvolvimento baseado na relação centro-periferia. Esse processo foi realizado de diferentes maneiras por esses países, implicando em resultados diferenciados para cada um deles. No caso do Chile, houve o rompimento precoce com a política de ISI, na década de 1970, como uma decisão de Estado, sendo adotado um modelo de desenvolvimento fundamentado no setor primário-exportador. $\mathrm{Na}$ atual conjuntura econômica internacional, em face da elevação dos preços dos produtos primários, essa estratégia de desenvolvimento adotada pelo Chile se mostra extremamente favorável, sobretudo ao ser conjugada com políticas econômicas anticíclicas nas áreas monetária, fiscal e cambial. Mas, apesar do crescimento econômico, este país não conseguiu promover a redução das desigualdades na sociedade chilena, havendo um aprofundamento da exclusão e marginalização sociais. Então, é necessário discutir como os países latino-americanos irão aproveitar a bonança econômica, baseada na valorização das commodities, porque esse processo é crucial para o próprio futuro da América Latina, sendo o Chile um caso paradigmático para estudo.

Palavras-chave: Bonança econômica, Desenvolvimento, CEPAL, Chile.

Abstract: The import substitution industrialization (ISI) was advocated by ECLAC/CEPAL thinking, especially in the 50s, as economic development strategy for Latin American countries to break the underdevelopment based on the center-periphery relationship. This process was carried out in different ways by these countries, involving for each one different results. Chile had an early break with ISI's policy, as in the 1970s, the State decided to adopt a model based on the primary export development. In the current international economic

(*) O presente artigo é oriundo de reflexões realizadas no Curso "Economia e Política Econômica da América Latina Hoje: Temas Relevantes, Países Selecionados - Argentina, Chile, México e Venezuela" ministrado pelo professor Dr. Carlos Eduardo Ferreira de Carvalho (PUC/SP), no $1^{\mathrm{O}}$ semestre de 2012, no âmbito da disciplina "Seminário Geral: Olhares Internacionais sobre a América Latina" no Programa de Pós-graduação em Integração da América Latina (PROLAM) da Universidade de São Paulo (USP).

(**) Doutoranda em Integração da América Latina pela Universidade de São Paulo (USP), Doutoranda em Direito Político e Econômico pela Universidade Presbiteriana Mackenzie. E-mails: <jcaravierigamba@uol.com.br> e <jcaravieri@usp.br>. Recebido em 26.09.2012 e aceito em 12.10.2012. 
situation, in the face of rising commodity prices, the strategy of development adopted by Chile shows extremely favorable, especially when combined with anti-cyclical economic measures in fiscal, monetary and exchange policies. However, instead of economic growth, this country has failed to promote the reduction of inequalities in Chilean society, leading to deeper social exclusion and marginalization. So, it is necessary to discuss how Latin American countries will take advantage of the economic bonanza based on the value of commodities, and why this process is crucial to the own future of Latin America, considering Chile as a paradigmatic case for study.

Keywords: Economic bonanza, Development, ECLAC/CEPAL, Chile.

A ocupação econômica das terras americanas constitui um episódio da expansão comercial da Europa. Não se trata de deslocamentos de população provocados por pressão demográfica - como fora o caso da Grécia - ou de grandes movimentos de povos determinados pela ruptura de um sistema cujo equilíbrio se mantivesse pela força - caso das migrações germânicas em direção ao ocidente e sul da Europa. O comércio interno europeu, em intenso crescimento a partir do século XI, havia alcançado um elevado grau de desenvolvimento no século XV, quando as invasões turcas começaram a criar dificuldades crescentes às linhas orientais de abastecimento de produtos de alta qualidade, inclusive manufaturas. $\mathrm{O}$ restabelecimento dessas linhas, contornando o obstáculo otomano, constitui sem dúvida alguma a maior realização dos europeus na segunda metade desse século. A descoberta das terras americanas é, basicamente, um episódio dessa obra ingente. De início, pareceu ser episódio secundário. E, em verdade o foi para os portugueses durante todo um meio século. Aos espanhóis reverteram em sua totalidade os primeiros frutos, que são também os mais fáceis de colher. O ouro acumulado pelas velhas civilizações da meseta mexicana e do altiplano andino é a razão de ser da América, como objetivo dos europeus, em sua primeira etapa de existência histórica. A legenda de riquezas inapreciáveis por descobrir corre a Europa e suscita um enorme interesse pelas novas terras. Esse interesse contrapõe Espanha e Portugal, "donos" dessas terras, às demais nações europeias. A partir desse momento, a ocupação da América deixa de ser problema exclusivamente comercial: intervêm nele importantes fatores políticos.

Celso Furtado

Formação Econômica do Brasil

\section{INTRODUÇÃO}

A industrialização substitutiva de importações (ISI) foi preconizada pelos estudos da Comissão Econômica para a América Latina e o Caribe (CEPAL), principalmente nos anos 50, como instrumento promotor do desenvolvimento dos países latino-americanos, no intuito de romper com o subdesenvolvimento baseado na relação centro-periferia.

Esse processo foi realizado de diferentes maneiras pelos países latino-americanos, implicando em "respostas" ou resultados diferenciados para cada um deles. No caso do Chile, objeto desse estudo, houve o rompimento precoce com a política de ISI na década de 1970, como uma decisão de Estado, sendo adotado um modelo de desenvolvimento econômico fundamentado no setor primário-exportador.

$\mathrm{Na}$ conjuntura econômica internacional vigente, em face da elevação dos preços dos produtos primários, essa estratégia de desenvolvimento se mostra extremamente favorável. Os preços das commodities apresentaram significativa elevação no começo 
deste século XXI, impulsionados pela ascensão da China, principalmente, e da Índia no cenário internacional como compradores desses produtos. "Os altos preços das matérias-primas obedecem sobretudo ao fato de que a economia chinesa depende fortemente das importações de produtos básicos." (OCAMPO, 2007, p. 79.) Apesar da crise financeira mundial ocorrida em 2008-2009, essa tendência de alta se confirmou após meados de 2009, demonstrando que a valorização dos produtos primários ainda se manterá por um longo período.

Nesse contexto, a América Latina ganha novamente importância no âmbito do comércio internacional, pois é abundante em recursos naturais (terra, água, sol, energia etc.) e em matérias-primas (hidrocarbonetos, produtos minerais e agrícolas etc.) necessários ao ávido consumo asiático o que pode impactar positivamente (ou não), neste século, nas economias latino-americanas de acordo com as políticas macroeconômicas e o modelo de desenvolvimento econômico adotado em cada país.

Entretanto, não se pode olvidar que esse "novo" cenário não está dissociado da trajetória histórica de formação econômica e social da América Latina, construída a partir do século XVI, que converteu os países latino-americanos em essencialmente exportadores de matéria-prima e mão de obra baratas.

Essa condição se acentuou com a inserção desses países na chamada divisão internacional do trabalho ${ }^{(1)}$ surgida com a Revolução Industrial (séculos XVIII e XIX) e aprofundada com o desenvolvimento do capitalismo financeiro, conforme Furtado (1970, p. 61-64) também aponta:

A inserção dos países latino-americanos nas novas linhas em expansão do comércio internacional realizou-se a partir dos anos quarenta do século passado. Nesse processo de inserção tendem a configurar-se três grupos de países exportadores de produtos primários: a) países exportadores de produtos agrícolas de clima temperado, b) países exportadores de produtos tropicais, e c) países exportadores de produtos minerais. Em cada um desses casos, o comércio exterior contribuiu para configurar uma estrutura econômica particular, cujas características devem ser tidas em conta no estudo de sua evolução subsequente.

O primeiro grupo de países foi essencialmente constituído pela Argentina e o Uruguai. A produção agrícola exportável baseou-se, neste caso, no uso extensivo da terra e se destinou a concorrer com a própria produção interna dos países em rápida industrialização. [...]

O segundo grupo, formado pelos países exportadores de produtos agrícolas tropicais, congregou mais da metade da população latino-americana. Nele se incluíram o Brasil, a Colômbia, o Equador, a América Central e o Caribe, bem como certas regiões do México e da Venezuela. A inserção desses países no comércio internacional se realizou em concorrência com áreas coloniais e com a região sul dos Estados Unidos. O açúcar e o fumo conservaram suas características de produtos tipicamente coloniais até fins do século XIX. [...]

(1) A divisão internacional do trabalho passou por diferentes etapas acompanhando o desenvolvimento histórico do capitalismo, iniciando com relações mercantilistas que marcaram o comércio entre metrópoles europeias e colônias de exploração latino-americanas, principalmente, até a configuração de relações entre países, chamados desenvolvidos, e outros considerados subdesenvolvidos ou não industrializados no âmbito do capitalismo global. 
O terceiro grupo de países, constituído pelos exportadores de produtos minerais, foi basicamente formado pelo México, o Chile, o Peru e a Bolívia. A Venezuela, como exportador de petróleo, se integrou ao grupo a partir do segundo decênio do século atual. [...]

Esse passado de colônias de exploração dos países latino-americanos desencadeou a formação de economias subdesenvolvidas que, no século XX, caracterizaram-se por uma industrialização tardia em alguns países e, em outros, por uma economia ancorada no modelo agrário exportador, havendo impactos diferenciados nos processos de desenvolvimento e crescimento econômico impulsionado por esse "novo" contexto internacional de significativa alta dos preços dos produtos primários.

Assim, o presente estudo dividiu-se em três partes. Primeiramente, analisou-se, de modo sucinto, o pensamento cepalino dos anos 50, basicamente a proposta de Raúl Prebisch acerca da industrialização substitutiva de importações (ISI) e seu impacto no desenvolvimento das economias latino-americanas. A seguir, debruçou-se sobre o estudo da chamada "bonança econômica" e suas perspectivas para o futuro dos países latino-americanos. Por fim, centrou-se a análise no modelo de desenvolvimento adotado no Chile o qual rompeu precocemente com o processo de ISI e caminhou noutra direção, principalmente as perspectivas atuais em face da conjuntura internacional de elevação dos preços dos produtos primários.

Então, diante da valorização das commodities no comércio internacional, é imperioso analisar as perspectivas para os países latino-americanos, em especial, como o Chile está aproveitando a "bonança econômica" para alavancar o desenvolvimento.

\section{O PENSAMENTO CEPAlino E O DESENVOlVimento ECONÔMICO LATINO- -AMERICANO}

No estudo das economias latino-americanas no século XX, ganhou evidência a tese de Raúl Prebisch sobre a deterioração dos termos de troca, em oposição à teoria das vantagens comparativas no comércio internacional, e as formulações de Celso Furtado que buscaram explicar o subdesenvolvimento da América Latina a partir de seu contexto histórico específico (uma teorização própria). "De acordo com Furtado, o subdesenvolvimento não é uma simples fase de transição ao desenvolvimento, mas um fenômeno mais permanente, cuja superação exige uma dedicação política tenaz e prolongada." (BIELSCHOWSKY, 2010, p. 190.)

As formulações teóricas de Prebisch e de Furtado se inseriram no âmbito dos estudos da Comissão Econômica para a América Latina e o Caribe (CEPAL). O pensamento cepalino se fundamentou numa teoria histórico-estruturalista que analisou o subdesenvolvimento dos países latino-americanos a partir da ideia do estabelecimento de relações entre países centrais e periféricos no comércio mundial ${ }^{(2)}$.

(2) Segundo Bielschowsky (2000, p. 27-28): "Prebisch já utilizava a expressão 'países periféricos' bem antes de ingressar na CEPAL (Love, 1980). A categoria servia-lhe até então para salientar a vulnerabilidade latino-americana aos ciclos econômicos, resultando em processos inflacionários com um forte componente exógeno e tendências a contrações cíclicas internas que, politicamente, potencializavam soluções macroeconômicas pouco recomendáveis. A violenta contração 
O pensamento cepalino se alicerçava, basicamente, nas seguintes diretrizes analíticas: enfoque histórico-estruturalista baseado na ideia de relação centro-periferia; análise da inserção internacional, principalmente no comércio, da América Latina; análise das condicionantes estruturais internas de cada país e estudo das necessidades e possibilidades de ação estatal em cada país para superar o subdesenvolvimento.

Assim, o estruturalismo na análise cepalina, segundo Bielschowsky (2000), é orientado para a busca de relações diacrônicas, históricas e comparativas que derivariam fundamentos essenciais para a análise do desenvolvimento econômico dos países latino-americanos. As concepções histórico-estruturalistas da CEPAL se constituíram num arcabouço analítico específico, aplicável a condições históricas próprias da periferia latino-americana.

Além disso, apenas para fins meramente elucidativos, verifica-se que o pensamento da CEPAL está dividido em fases ou etapas, conforme elaborado por Bielschowsky (2000, p. 18-19), em que cada uma corresponde aproximadamente a uma década de história e propõe prognósticos diferenciados para a resolução dos problemas das economias latino-americanas:

a) anos 1950: industrialização substitutiva de importações;

b) anos 1960: reforma agrária e distribuição de renda para desobstruir a industrialização;

c) anos 1970: reorientação do desenvolvimento visando à industrialização que combine mercado interno e exportações;

d) anos 1980: superação do problema do endividamento externo mediante o "ajuste com crescimento";

e) anos 1990: implementação da transformação produtiva com equidade.

Para melhor compreensão do impacto da alta dos preços dos produtos primários para o desenvolvimento econômico na América Latina na atualidade, será pertinente a realização de algumas considerações sobre a primeira etapa do pensamento cepalino centrado na proposta de industrialização substitutiva de importações.

Nesse contexto, está inserido o estudo mais significativo de Raúl Prebisch: "O Desenvolvimento Econômico da América Latina e Alguns de seus Problemas Principais" de 1949, conhecido como "Manifesto Cepalino". Ele apontou questões fundamentais que norteariam o pensamento econômico estruturalista da CEPAL e orientariam o processo de desenvolvimento implantado na América Latina a partir dos anos 50: a evidência empírica da deteriorização dos termos de troca de modo desfavorável para os países da América Latina, afrontando o postulado liberal das virtudes do comércio internacional livre.

da capacidade para importar nos anos 1930 e suas repercussões sobre as economias latino-americanas constituíram a referência histórica principal para a elaboração, por parte de Prebisch, da distinção entre o modo de funcionamento das economias dos países industrializados e aquele encontrado em economias especializadas em bens primários. $\mathrm{Na}$ CEPAL o argumento ganhou contundência logo nos textos inaugurais, porque foi acompanhado da tese da tendência à deterioração dos termos de troca, que afrontava o postulado liberal das virtudes do comércio internacional livre. Ao contrário do que prometia a teoria das vantagens comparativas, durante o século XX a maior lentidão no progresso técnico dos produtos primários em relação aos industriais não estava motivando o encarecimento dos primeiros com relação aos últimos.". 
De modo sucinto, as ideias centrais de Prebisch (2000a, p. 69-93) eram:

a) ocorrência da deterioração dos termos de troca, no comércio internacional, desfavoravelmente às economias latino-americanas em oposição à teoria ricardiana das vantagens comparativas;

b) estrutura heterogênea da produção impedindo que a periferia retivesse os progressos técnicos, diferentemente do que ocorria nos países de economia central;

c) grande contingente de mão de obra rural como potencial para a contínua expansão da oferta de bens primários no mercado mundial e sua consequente queda de preços;

d) ainda que baixa, a eficiência industrial na periferia seria superior à eficiência no setor agrícola;

e) até a conclusão do processo de ISI, a periferia continuaria sofrendo problemas com a balança de pagamentos o que seria a causa da inflação estrutural existente.

Em face dessas constatações, utilizando-se do argumento da indústria nascente ${ }^{(3)}$, Prebisch defendeu a necessidade de se implementar nos países latino-americanos políticas de industrialização para superar o subdesenvolvimento e a pobreza. Nesse sentido, ele propôs que, num primeiro momento, seria necessária a industrialização pela "política de substituição de importações”, sendo um processo desenvolvido sob o amparo de medidas protecionistas do Estado. Isto permitiria a existência de efeitos dinâmicos para o desenvolvimento latino-americano, pois a indústria proporcionaria maior progresso não apenas no campo econômico, mas também político e social.

Verificando que a divisão internacional do trabalho, até então existente, era prejudicial para a América Latina e favorável apenas às economias dos países industrializados ${ }^{(4)}$, Prebisch propôs a ISI como alternativa. Porém, a ISI não seria o objetivo final das suas propostas, encampadas pela CEPAL, mas um instrumento em direção a um projeto maior: o aumento da participação da América Latina no comércio internacioal de manufaturas e o desenvolvimento de um mercado comum latino-americano. Essas ideias seriam melhor desenvolvidas por Prebisch nos seus escritos pós-1949.

(3) O argumento da indústria nascente possui cunho econômico, sendo utilizado como justificativa para a tomada de medidas protecionistas em prol do desenvolvimento industrial. Ele está relacionado à eficácia da intervenção governamental (a atuação do Estado) sobre determinados ramos de produção no intuito de promover o desenvolvimento econômico do país. Stuart Mill foi um dos economistas pioneiros na análise do tema da indústria nascente, principalmente na obra "Princípios de Economia Política" publicada pela primeira vez em 1848, e defendeu o uso de medidas protecionistas, ainda que temporariamente - especialmente no caso de países "jovens" e em processo de desenvolvimento — para dinamizar determinados setores industriais e adequá-los às circunstâncias do país. Mill (1983) aponta que as medidas protecionistas devem ser mantidas apenas de modo temporário como estímulo à indústria nascente porque, a médio e longo prazo (a proteção possui certo limite de duração), sobretudo durante o processo de "amadurecimento" das indústrias, o protecionismo se mostra inconveniente e inadequado para dinamizar a economia e estimular o desenvolvimento sustentado. Deve-se assegurar gradual decrescimento das medidas protecionistas até que sejam completamente dispensadas pela indústria que, então, mediante as "forças" do próprio mercado devem se tornar competitivas. Em síntese, o argumento de Mill sobre a indústria nascente sugere a existência de efeitos dinâmicos para o desenvolvimento - $\mathrm{a}$ indústria proporcionaria um maior progresso não apenas no campo econômico, mas também político e social — que não seriam considerados pela teoria clássica ricardiana das vantagens comparativas. Raúl Prebisch incorporou, em sua análise econômica da América Latina, a necessidade de adoção do protecionismo para a indústria nascente latino-americana no intuito de promover o desenvolvimento econômico da região.

(4) Relação de dependência centro-periferia de modo que os países latino-americanos eram exportadores de matérias-primas e importadores de bens industriais com maior valor agregado. 
Segundo Braga (2008, p. 96):

"[...] as propostas protecionistas que de fato estiveram presentes nos documentos iniciais da CEPAL não tinham a intenção de reduzir a participação da América Latina no comércio internacional. A substituição de importações não era um fim em si mesmo, mas uma etapa anterior a um processo mais amplo: uma vez estabelecidas as transformações necessárias para o rompimento das relações 'centro-periferia', a América Latina poderia e deveria ampliar a sua participação no comércio internacional. Uma conclusão totalmente oposta àquelas defendidas pelos que encaram este 'velho regionalismo' e, de uma forma geral, o processo de substituição de importações como verdadeiras conspirações contra o livre-comércio."

Desse modo, Prebisch não era contrário ao livre-comércio, mas pretendia que a América Latina se inserisse no comércio mundial de manufaturas (não de alta tecnologia, mas sim de produtos mais simples) ao implementar internamente a industrialização via substituição de importações e isso implicava necessariamente no uso do argumento da indústria nascente com medidas protecionistas.

O processo de substituição de importações foi apregoado, nesta primeira fase do pensamento cepalino, não como um fim em si mesmo, mas como um meio para promover o desenvolvimento econômico dos países latino-americanos e inseri-los, de modo mais competitivo, no comércio mundial de manufaturas, havendo reflexos em outras áreas, inclusive com transformações no aspecto social.

Assim, esses países iriam se industrializar e implementar uma estrutura produtiva direcionada à produção de bens manufaturados mais simples e não de alta tecnologia, de modo a estimular o intercâmbio com os países desenvolvidos.

No documento de 1959, intitulado "O Mercado Comum Latino-americano", Raúl Prebisch demonstrou que estava ciente das limitações da ISI que possuiria apenas um caráter transitório; apontou a necessidade do aumento da participação da América Latina no comércio mundial de manufaturas e a necessidade de se desenvolver um mercado comum latino-americano, pois a integração econômica regional se apresentava como forma de superar as limitações da região ao desenvolvimento. Nesse sentido, destacam-se as assertivas de Prebisch (2000b, p. 358-359):

A outra possibilidade de atenuar a queda do coeficiente de importações seria a exportação de manufaturas de países da América Latina para outras partes do mundo. [...] A possibilidade de esse tipo de intercâmbio industrial se expandir depende de dois fatores: por um lado, a capacidade de exportação da América Latina e, por outro, a disposição dos grandes centros de facilitar as importações correspondentes, mediante um tratamento tarifário adequado. Quanto ao primeiro fator, o mercado comum, ao contribuir para a redução dos custos, poderá dar um impulso decisivo a algumas linhas da exportação industrial. É preciso reconhecer que as facilidades criadas no mercado interno pela política de substituição de importações não deram margem, até agora, a iniciativas de peso em matéria de exportações industriais para o resto do mundo. [...] Assim, podemos conceber formas reciprocamente vantajosas de intercâmbio industrial, que são muito diferentes, por sua significação, da tradicional troca de matérias-primas por produtos industrializados. Tudo isso evidencia que a política 
de mercado comum latino-americano, tal como foi concebida, longe de conspirar contra o comércio internacional, poderia estimulá-lo.

Neste documento de 1959, Prebisch evidencia que o sucesso do processo de ISI somente seria completo mediante criação do mercado comum latino-americano, ou seja, de um bloco econômico regional que estimularia o comércio tanto entre os países latino-americanos como também com os países desenvolvidos. Assim, a região latino-americana teria um ganho de escala - em função da ampliação dos mercados - dinamizando o comércio regional. Segundo Prebisch (2000b, p. 362-363):

[o mercado comum] oferece uma alternativa à política de substituição de importações: adquirir em outros países latino-americanos os produtos industriais que antes eram importados do resto do mundo, pagando por eles com um aumento das exportações. [...] a vantagem do mercado comum está em que ele oferecerá a oportunidade de realizar essas exportações para outros países da América Latina, a fim de adquirir neles, folgadamente, as importações que já não possam ser trazidas do resto do mundo. [...]

O mercado comum não apenas permitirá diversificar as exportações, ao agregar exportações industriais às dos produtos primários, como também diversificar as importações. Tudo isso contribuirá para atenuar a vulnerabilidade externa dos países latino-americanos.

Portanto, Prebisch demonstrou que estava ciente das limitações da industrialização substitutiva de importações e apontou a necessidade de se desenvolver o mercado comum latino-americano como alternativa para superar o subdesenvolvimento na região, aprofundando a integração regional por um comércio mais intenso e dinâmico.

Essa visão constituiu o chamado "velho regionalismo" e concretizou-se pela criação da Associação Latino-americana de Livre Comércio (ALALC) — criada em 18.2.1960 pelo Tratado de Montevidéu - como alternativa para superar o subdesenvolvimento dos países latino-americanos, aprofundando a integração por um comércio mais intenso e dinâmico entre os países da região. Conforme Bielschowsky (2000, p. 30) preceitua:

A argumentação cepalina a favor da ALALC continha a ideia de iniciar um processo de diversificação das exportações por esforço próprio, através da via teoricamente mais fácil do comércio intrarregional. Mais importante ainda, e conforme se lê nas seções introdutórias do texto cepalino inaugural sobre o tema (CEPAL, 1959) redigido por Prebisch —, o mercado comum latino-americano teria a virtude de ampliar o tamanho do mercado dos setores industriais exigentes em escala, facilitando o aprofundamento do processo produtivo.

A ALALC foi uma organização intergovernamental, sedimentada no reconhecimento da "cláusula da nação mais favorecida" e, teoricamente, no princípio da reciprocidade entre as partes, mas, na prática, vários obstáculos ${ }^{(5)}$ minaram sua consolidação como um mercado comum.

(5) Podem ser destacados os seguintes: a) não havia uma infraestrutura regional adequada que permitisse a consolidação do comércio entre os países latino-americanos; b) instabilidade macroeconômica crescente, havendo forte endividamento externo, altas taxas de inflação, instabilidade cambial etc.; c) ausência de políticas macroeconômicas coordenadas; d) implantação de ditaduras militares e governos autoritários que minaram as negociações multilaterais no bloco, pois não havia como viabilizar a integração sem uma democracia; d) instabilidade política e institucional nos países integrantes da organização; e) dificuldade de cooperação regional, principalmente num contexto de regimes ditatoriais, entre outros fatores (Ffrench-Davis e Munoz, 2009 e Braga, 2002). 
A respeito do insucesso da ALALC e da consolidação do mercado comum latino-americano, Ffrench-Davis e Munoz (2009, p. 188) apontam três problemas principais:

a) falhas internas do próprio Tratado de Montevidéu, tais como: não ter incluído mecanismos efetivos para criar tarifas externas comuns para todos os países-membros; carência de medidas adequadas para realizar uma distribuição equitativa dos benefícios entre os países signatários; não se deu atenção suficiente à necessidade de harmonizar as políticas macroeconômicas entre os países participantes da ALALC;

b) houve a falta de vontade política dos países mais importantes que integravam a organização;

c) o antagonismo à liberalização do comércio, expresso pelos produtores de sucedâneos produtos importados, no intuito de manter um controle monopolista sobre os principais mercados nacionais.

Como a ALALC não obteve sucesso, a ISI se transformou num objetivo em si mesmo e não permitiu o desenvolvimento econômico para a América Latina nos contornos propostos pelo pensamento cepalino. Portanto, apesar das boas intenções e de bons resultados inicialmente obtidos com o incremento de alguma parcela de comércio na região, a ALALC não conseguiu resistir aos problemas econômicos e políticos, havendo a paralisação das negociações multilaterais e a sua dissolução ${ }^{(6)}$.

Somente a partir dos anos 80, a integração econômica regional novamente ganhará destaque no cenário latino-americano, sobretudo em função do término de longo período de governos autoritários (ditaduras militares) que haviam se constituído nos países da região e, ainda, em razão de perspectivas de maior estabilidade econômica, particularmente relacionadas ao controle da hiperinflação.

A partir das lições deixadas pela crise econômica dos anos 80 (a chamada década perdida), a CEPAL elaborou a proposta de uma integração regional num novo "formato", o chamado regionalismo aberto, baseada numa transformação das estruturas produtivas da região conjugada com maior equidade social - a "Transformação Produtiva com Equidade" - que foi o cerne do pensamento cepalino na década de 90 . O regionalismo aberto pode ser assim definido:

[...] denomina-se "regionalismo aberto" o processo que surge ao serem conciliados dois fenômenos [...]: a interdependência nascida de acordos especiais de caráter preferencial e a que é basicamente impulsionada pelos sinais do mercado, resultantes da liberalização comercial em geral. O que se busca com o regionalismo aberto é que as políticas explícitas de integração sejam compatíveis com as políticas tendentes a elevar a competitividade internacional, além de complementares a elas.

(6) A respeito do insucesso da ALALC e da consolidação do mercado comum latino-americano, Braga (2002, p. 12-14) dispõe que: "[...] podemos destacar, inicialmente, as dificuldades em se distribuir os benefícios e custos da integração em um grupo de países com diferentes graus de desenvolvimento industrial e que demandam a difícil tarefa da administração de conflitos entre os estados nacionais. Tais dificuldades estavam previstas no documento de 1959, através do chamado 'princípio da reciprocidade'. Tal princípio [...] buscava assegurar a todos os países participantes do mercado comum os benefícios na medida das concessões. Trata-se de um processo de difícil coordenação e que envolve não apenas questões econômicas mas também políticas, principalmente quando não existe uma clara definição das estratégias de desenvolvimento a serem seguidas, ou quando tais estratégias criam uma elite industrial com influência política e que se opõe a uma maior abertura da economia às importações." 
O que diferencia o regionalismo aberto da abertura e da promoção indiscriminada das exportações é que ele inclui um ingrediente preferencial, refletido nos acordos de integração e reforçado pela proximidade geográfica e pela afinidade cultural dos países da região. (CEPAL, 2000, p. 945)

À luz dessa concepção de regionalismo aberto, a integração deveria ser conduzida não apenas pelos Estados, mas também pelos agentes privados responsáveis pelas relações produtivas e tecnológicas, havendo um processo "autônomo" de integração via estratégias empresariais que demandaria ações mais específicas em seu favor no contexto da globalização. Nesse contexto, houve a criação do MERCOSUL como bloco econômico de integração regional, tendo o desafio de sua conversão em mercado comum com livre circulação de bens, serviços, pessoas e capitais. Porém, essa nova fase do pensamento cepalino - "Transformação Produtiva com Equidade" — não será objeto de análise específica no presente estudo, podendo ser aprofundada numa outra oportunidade.

Portanto, o pensamento da CEPAL foi extremamente importante para a adoção de modelos diferenciados de desenvolvimento econômico pelos países latino-americanos, principalmente a partir dos anos 50 , sendo essencial a proposta de ISI desenvolvida por Prebisch.

Entretanto, o Chile resolveu adotar uma estratégia de desenvolvimento econômico baseada no uso dos recursos primários, rompendo com o processo de ISI e caminhando noutra direção, o que o torna um caso paradigmático para estudo.

\section{BONANÇA ECONÔMICA E DESENVOLVIMENTO: PERSPECTIVAS PARA O FUTURO DA AMÉRICA LATINA}

A ISI foi preconizada pelo pensamento cepalino como instrumento para o desenvolvimento econômico dos países latino-americanos, de modo a alterar a estrutura econômica existente, rompendo com o subdesenvolvimento baseado na relação centro-periferia. Esse processo foi realizado de diferentes maneiras pelos países latino-americanos, implicando em "respostas" ou resultados diferenciados para cada um deles, sendo objeto desse estudo o caso chileno. Segundo Ffrench-Davis e Munoz (2009, p. 161):

Apesar de cada país ter tentado, em certa medida, seguir seu próprio caminho de industrialização, a maioria dos países da América Latina, da década de 50 à de 80 , tiveram em comum a característica básica de transformar o setor industrial no principal motor de crescimento. É possível, portanto, falar nesse período de uma experiência comum latino-americana de desenvolvimento, embora os instrumentos de política, o momento, a intensidade e as realizações de seus processos de industrialização possam ser diferentes.

No contexto atual mais amplo, a bonança econômica foi favorecida por fatores que não ocorriam desde os anos 1970, conforme aponta Ocampo (2010, p. 79-80):

[...] bons preços das matérias-primas e excepcionais condições de financiamento externo. A histórica econômica da América Latina mostra que tal combinação conduz inequivocadamente a um rápido crescimento econômico. Contudo, na conjuntura atual os 
mecanismos de transmissão são um pouco diferentes em matéria de financiamento externo, sobretudo porque os governos usaram esse financiamento com muito mais cautela. A estes dois fatores devemos acrescentar um terceiro: as vultosas remessas dos migrantes latino-americanos a seus países de origem. Este elemento tem pesado muito nas economias geograficamente mais próximas dos Estados Unidos [...] este é o primeiro período da história econômica mundial no qual o PIB por habitante dos países em desenvolvimento cresce muito mais que o do mundo industrializado - quer dizer, rompeu-se a tendência divergente dos níveis de desenvolvimento dos dois conjuntos de países que caracterizou a história econômica mundial (Nações Unidas, 2006). [...]

A grande novidade na conjuntura atual é a capacidade de crescer com rapidez, gerando ao mesmo tempo um superávit em conta corrente e, portanto, uma transferência líquida de recursos ao exterior. Esta combinação, que é uma característica das economias dinâmicas do leste da Ásia, não tem precedentes na história da região [América Latina]. (grifo nosso)

Em face dessa bonança econômica, surgem desafios para os países latino-americanos, principalmente no plano do desenvolvimento econômico que envolve a chamada "macroeconomia dos recursos naturais" (7). Ainda não se sabe quanto tempo essa bonança irá durar, mas a tendência de alta dos preços dos produtos primários se confirmou após meados de 2009, demonstrando que ainda se manterá por um longo período (OCAMPO, 2007; BACHA E FISHLOW, 2011); talvez, o ciclo seja de até vinte anos. Esse processo vem em direção totalmente inversa à proposta cepalina de ISI para o desenvolvimento da América Latina.

Então, o principal desafio dos países latino-americanos, que se beneficiam dessa alta dos produtos primários no comércio internacional, será a disseminação da riqueza gerada nesse setor primário-exportador para outras áreas da economia juntamente com o desenvolvimento tecnológico e a promoção do crescimento econômico.

Em relação às possíveis ameaças que esse processo de bonança econômica pode gerar, essencialmente com a valorização dos produtos primários, destacam-se as assertivas de Bacha e Fishlow (2011, p. 02-03):

Em 2010, a América Latina estava crescendo de novo e os preços das commodities se fortaleciam. É uma combinação feliz, mas não deixa de ter contradições. A tensão principal é antiga, e aparece com o nome de "desindustrialização" ou "doença holandesa": à medida que os recursos internos são atraídos para os setores relacionados com as commodities, há uma tendência de apreciação da taxa de câmbio real e, em consequência, de perda de competitividade dos setores que não têm relação com as commodities, com risco de perderem espaço tanto no mercado internacional quanto no mercado interno. [...]

Essa não é a única tensão derivada do boom recente nos preços das commodities, pois a taxa de câmbio pode se apreciar não como consequência direta das exportações de commodities, mas sim por causa da entrada de capitais atraídos pela melhora

(7) Este termo foi utilizado em sala de aula pelo Professor. Dr. Carlos Eduardo Ferreira de Carvalho da PUC/SP. 
nas perspectivas econômicas da região. Por conseguinte, o que está em jogo não é apenas uma velha controvérsia sobre padrões de industrialização, mas uma nova controvérsia sobre entrada de capitais e déficits simultâneos em conta corrente. E aí está envolvida também a questão das taxas de juros domésticas e seu nível adequado.

Ainda no âmbito da macroeconomia dos recursos naturais e sua relação com o desenvolvimento econômico, também se apresentam como ameaças aos países latino-americanos, conforme aponta a literatura, as denominadas "maldição dos recursos naturais" e "doença holandesa".

No primeiro caso, haveria uma relação inversa entre a taxa de crescimento de um país e sua riqueza em recursos naturais; os "países bem-dotados de recursos naturais tenderiam a crescer em ritmo inferior aos países não tão bem-dotados" (BACHA E FISHLOW, 2011 , p. 05). Entretanto, a literatura econômica ${ }^{(8)}$ já indica que "a maldição é a da falta de diversificação e não a dos recursos naturais. [...] [pode haver atraso no] crescimento devido à limitadas possibilidades de variação entre as commodities [...] é factível a diversificação para outros setores a partir de uma base forte em recursos naturais, como ilustram os países nórdicos e os anglo-saxões do novo mundo que são hoje países bem desenvolvidos" (BACHA E FISHLOW, 2011, p. 08).

No segundo caso, a bonança de recursos naturais seria maléfica para os países produtores porque geraria uma tendência à "desindustrialização". De acordo com Bacha e Fishlow (2011, p. 11), a doença holandesa:

[...] surge quando uma alta expressiva, mas talvez temporária, no preço internacional de uma commodity de exportação provoca uma forte apreciação cambial, um aumento nos preços dos bens locais relativamente aos bens comercializados internacionalmente não produtores de commodities, um consequente êxodo de insumos desses últimos setores, e um déficit em conta corrente (Frankel, 2010). Quando estão no setor manufatureiro os bens que sofrem o crowding out, o efeito temido é a desindustrialização. [...] não se pode prever adequadamente o ciclo completo, e que tudo será dolorosamente revertido quando o preço internacional da commodity de exportação voltar a cair. Pode então ocorrer uma fuga de capitais, acelerando a depreciação do câmbio em meio a uma crise de balanço de pagamentos.

Entretanto, é preciso destacar que está ocorrendo em todo o mundo uma tendência de perda da relevância da indústria, inclusive em países altamente industrializados, ou seja, a indústria está perdendo sua participação no PIB para outros setores da economia, principalmente para a área dos serviços. Logo, essa tese da desindustrialização dos países produtores de commodities deve ser vista com ressalvas no caso da América Latina.

Além disso, "os elevados preços das commodities de forma continuada nos próximos anos poderiam proporcionar recursos valiosos para acelerar o desenvolvimento econômico e social dos países exportadores de commodities com boas políticas e boa governança" (BACHA E FISHLOW, 2011, p. 10), o que se enquadraria perfeitamente no caso chileno.

(8) Bacha e Fishlow (2011) fazem referência aos seguintes artigos: LEDERMAN, D. and MALONEY, W. (eds). Natural resources: neither curse nor destiny, Palo Alto, Calif. and Whashington, DC: Stanford University Press and World Bank, 2007 e LEDERMAN, D. and XU, L. Comparative advantage and trade intensity: are traditional endowments destiny? In: LEDERMAN, D. and MALONEY, W. (eds.). Natural resources: neither curse nor destiny, op. cit., 2007. 
No plano da política econômica propriamente dita, o desafio dos países latino-americanos seria a adoção de políticas anticíclicas nas áreas monetária, fiscal e cambial para a promoção do desenvolvimento. A partir de 1990, na maioria dos países latino-americanos, o paradigma neoliberal ou Consenso de Washington direcionou as políticas econômicas a serem adotadas na região.

As sucessivas crises internacionais ocorridas em 2007, 2008 e 2009 vem testando a credibilidade e sustentabilidade dessas políticas econômicas liberais, mas os países latino-americanos não as alteraram de modo significativo, demonstrando que elas estavam dando respostas adequadas às crises. Nesse sentido, Frenkel e Rapetti (2011, p. 29) dispõem:

Así, en los años 2000 varios países da región instrumentaron políticas macroeconómicas que combinan prudencia en el manejo fiscal, una política monetaria con esquemas de metas de inflación, una política cambiaria de flotación administrada y la acumulación preventiva de reservas. Con esta configuración macroeconómica, estos países lograron mantener niveles bajos de inflación y transitaron sin mayor dificultad el stress-test de la crisis financiera internacional de 2008-09, evitando recesiones prolongadas y crisis externas y financieras.

Portanto, em termos gerais, essa conjuntura internacional de bonança econômica, com expressiva elevação dos preços dos produtos primários, está beneficiando os países latino-americanos, desde que adotem políticas macroeconômicas mais contidas — normalmente anticíclicas - e usem a boa governança para lidar com essa situação.

\section{A "BONANÇA ECONÔMICA" E O MODElO DE DESENVOLVIMENTO ECONÔMICO CHILENO}

Na conjuntura econômica internacional de bonança econômica em andamento desde 2003, o modelo de desenvolvimento adotado pelo Chile se mostra extremamente promissor. A experiência chilena vem sendo observada como paradigma de desenvolvimento econômico entre os países latino-americanos, principalmente porque baseou sua economia no setor primário-exportador, sendo sua pauta exportadora dominada pelo cobre e outros produtos primários, tais como: frutas, vinhos, bacalhau etc.

A bonança econômica existente e o caso específico do Chile apontam em sentido totalmente inverso à proposta cepalina e de Raúl Prebisch - implantação da ISI como estratégia de desenvolvimento econômico — , sendo um paradoxo na atualidade para estudo.

O Chile rompeu precocemente, em 1973, com a proposta cepalina de ISI, como uma decisão de Estado, e adotou um modelo de desenvolvimento econômico fundamentado no setor primário. Houve a realização da "desmontagem" da industrialização (proposta de reindustrialização para "trás"), ou seja, houve o incentivo para indústrias de máquinas e equipamentos que estão atrás das cadeias produtivas. Conforme destaca Rouquié (1991, p. 279):

O Chile foi durante alguns anos o laboratório dos Chicago Boys, discípulos do guru monetarista de Illinois. Para o regime do general Pinochet, tratava-se de assegurar um "futuro sem inquietações nem temores", encarregando-se o "Deus-mercado" de 
exterminar duradouramente os demônios do coletivismo. A fim de restabelecer os mecanismos do mercado e criar um novo polo de crescimento - as exportações não tradicionais —, liberaram-se os preços, e as restrições que "pesavam" sobre as relações de trabalho foram suprimidas. Enquanto os impostos indiretos se elevavam e eram eliminadas as subvenções ao consumo popular, as despesas públicas, especialmente no domínio social, sofreram uma brutal amputação. A fim de permitir uma reestruturação das indústrias, os direitos alfandegários passaram de 100 a 10\%, enquanto a supervalorização do peso em relação ao dólar aumentava as importações. De mais a mais, em 1976 o Chile se retirou do Pacto Andino a fim de atrair os capitais, subtraindo-os às limitações e proibições comunitárias. A supressão da maior parte dos controles estatais, a desnacionalização das empresas socializadas pelo regime da Unidade Popular (1970-1973) e uma contrarreforma agrária complementaram esse tratamento de choque do qual se esperava o "milagre chileno". Obteve-se, certamente, uma diminuição da inflação relativamente espetacular, pois a alta dos preços caiu de 500\% em 1973 a 30\% em 1978, mas a um custo considerável. O PNB per capita era, em 1978, inferior ao de 1970. Se a recuperação econômica é inegável com taxas de crescimento médias superiores a 7\% anuais entre 1976 e 1980, o investimento estaciona então a um nível inferior ao dos anos 60 e 70. A parte da indústria na produção global decresce enquanto $90 \%$ dos investimentos estrangeiros dirigem-se ao setor mineiro. Em nome das vantagens comparativas, o Chile subdesenvolve-se. (grifo nosso)

Então, do ponto de vista da macroeconomia dos recursos naturais, o Chile — sob o controle dos "Chicago Boys" (monetaristas neoliberais) - adotou o setor primário-exportador como modelo de desenvolvimento econômico, beneficiando-se de suas riquezas naturais e rompendo definitivamente com a política de ISI. "Suas principais exportações, além do cobre, incluem frutas e vegetais, produtos florestais, pescado e vinho. As exportações representam mais de $40 \%$ do PIB, sendo o cobre a metade delas. A recíproca é o acesso a uma variedade de produtos manufaturados importados de qualidade mais alta e preços menores do que o que poderia ser produzido internamente." (BACHA E FISHLOW, 2011, p. 18.)

A conjuntura internacional vigente de bonança econômica é extremamente favorável ao Chile e indica que houve acerto em seu modelo de desenvolvimento com foco no setor primário-exportador em face da elevação dos preços dos produtos primários no mercado internacional, principalmente do cobre após 2003. Diz-se, na literatura econômica, sobre a existência de uma "bonança do cobre" que beneficiará ainda mais o Chile:

El precio del cobre está llegando a niveles récord históricos [...] Después de haber alcanzado en los años 2000-2002 el trienio de menor precio del cobre desde la Gran Depresión, hoy día estamos pontualmente en valores superiores a los máximos promedios anuales históricos. Si lograremos o no batir este récord dependerá de la persistencia del aumento que estamos observando, pero certamente, nuestras proyecciones son que en términos reales tendremos el precio promedio anual más, es razonable pensar que el precio del cobre puede seguir aumentando algo más, es razonable pensar que este debiera retroceder. El problema es que no sabemos hasta donde puede llegar ni cuándo se devolverá y es en 
este escenario de incertitumbre en el cual debemos hacer nuestras políticas económicas. (GREGORIO, 2006, p. 18)

No caso chileno, sua estratégia de desenvolvimento econômico baseada no uso dos recursos primários permitiu a geração de renda e riqueza que foram utilizadas em outras áreas da economia - diferentemente da Venezuela que não conseguiu "transbordar" a riqueza do petróleo para outras áreas —, favorecendo o crescimento econômico.

Além disso, o Chile, no plano da política econômica propriamente dita, também sob o comando dos "Chicago Boys", adotou políticas anticíclicas nas áreas monetária, fiscal e cambial para a promoção do desenvolvimento. Houve a abertura da economia chilena aos capitais externos e as reformas liberais permearam toda a estrutura da economia.

Em relação à fiscalidade, houve a diminuição dos gastos públicos, principalmente na área social, privatização da educação, da previdência social, do setor de produção do cobre etc. No âmbito da política monetária, houve a proposta de redução gradual da inflação com o uso de sistema de metas — não se trata de inflação zero e nem de processo de deflação - , de modo que o único instrumento do governo para controle da política seria a taxa de juros doméstica. Finalmente, a política cambial se baseou no uso de taxa de câmbio flutuante, sobretudo depois da crise de 1982, após a baixa do preço do cobre.

O caso chileno demonstra que não se concretizaram, até o presente momento, as teses da maldição dos recursos naturais e da doença holandesa que levaria à desindustrialização (BACHA E FISHLOW, 2011, p. 19). Ao contrário, o desenvolvimento econômico centralizado no setor primário-exportador e associado a políticas macroeconômicas anticíclicas, permitiu ao Chile o rígido controle da inflação e dos gastos públicos, concomitantemente com um crescimento econômico superior a muitos países latino-americanos.

Entretanto, apesar desse desempenho econômico ser tão promissor, o Chile não conseguiu promover uma distribuição adequada dos benefícios sociais para todas as áreas, sendo este um dos pontos negativos do modelo de desenvolvimento chileno. Apesar de ter duplicado o ingresso de renda per capita nas últimas décadas, ainda há significativa pobreza absoluta, não se verificou níveis adequados de vida para a maioria da população e a exclusão social aumentou (INFANTE E SUNKEL, 2009, p. 136).

Visto que no Chile houve crescimento econômico com a manutenção da desigualdade social, a literatura aponta a necessidade de se implantar um crescimento com equidade para que haja desenvolvimento com maior inclusão social:

El crecimiento acelerado y sostenido de la producción de bienes y servicios de consumo es condición essencial y directa del mejoramiento de los niveles de vida de la población. Este crecimiento, que en el pasado ha sido excluyente y há privilegiado a una minoria de la población, debe reunir una serie de requisitos especiales para que el desarrollo pueda ser inclusivo. (INFANTE E SUNKEL, 2009, p. 151)

Finalmente, para superar essa exclusão social existente no Chile, Infante e Sunkel (2009, p. 137 e p. 150) propõem ainda:

[...] para enfrentar decididamente este problema haya que pensar en cambiar radicalmente el enfoque de las políticas públicas, adoptando una estrategia de desarrollo inclusivo que permita superar gradualmente la heterogeneidad estructural prevaleciente en los 
diferentes estratos, sectores y regiones de la matriz productiva y social del país, puesto que [...] además de la concentración de la riqueza y el mal funcionamento del mercado de trabajo, esa diversidad es uno de los principales obstáculos que impieden lograr el crecimiento con equidad y contribuir así a mejorar la convivencia ciudadana y la democracia. [...]

La formulación de una nueva concepción del desarrollo nacional provista de un enfoque integral a mediano y largo plazos en que participen el Estado, la ciudadanía organizada, los trabajadores y el empresariado, exige câmbios institucionales en los ámbitos económico, laboral y de diálogo social. [...] Las políticas públicas deben cambiar y orientarse prioritariamente a elevar la productividad, poniendo especial énfasis en el mejoramiento del entorno en que se mueven las empresas pequenas y medianas, que son las que generan la mayor parte del empleo productivo. [...]

Nesse sentido, o Chile é um caso a ser analisado de modo mais profundo, inclusive em estudos futuros, pois conseguiu - inversamente à proposta cepalina da ISI - promover o desenvolvimento econômico com base no setor primário exportador e adotou políticas econômicas anticíclicas que trouxeram maiores equilíbrios macroeconômicos.

No entanto, ele é um país que ainda apresenta elevada concentração de renda e desigualdades sociais, devendo se ter maior esmero em apreciá-lo como modelo de desenvolvimento a ser utilizado por outros países latino-americanos.

\section{CONCLUSÃO}

A proposta da CEPAL, principalmente dos anos 50, de industrialização substitutiva de importações (ISI) possibilitaria o desenvolvimento dos países latino-americanos, superando os problemas da dicotomia centro-periferia. Esse processo foi realizado de diferentes maneiras pelos países latino-americanos, implicando em "respostas" ou resultados diferenciados para cada um deles.

$\mathrm{Na}$ atual conjuntura econômica internacional, em face da elevação dos preços dos produtos primários - impulsionada pela ascensão da China e da Índia no cenário internacional como compradores destes produtos - essa estratégia de desenvolvimento se mostra extremamente favorável.

Nesse contexto, a América Latina — abundante em recursos naturais e em matérias-primas - ganhou novamente importância para o comércio internacional, o que pode impactar positivamente, ou não, nas economias latino-americanas. Entretanto, esse "novo" cenário não está dissociado da trajetória histórica de formação econômica e social da América Latina, construída a partir do século XVI, que a inseriu na divisão internacional do trabalho e converteu-a em exportadora de matéria-prima e mão de obra baratas.

Em face da atual bonança econômica, surgem desafios para os países latino-americanos, principalmente no plano do desenvolvimento econômico, envolvendo a chamada "macroeconomia dos recursos naturais", e das políticas macroeconômicas a serem adotadas 
em cada um deles. Até o presente momento, não se sabe quanto tempo essa bonança irá durar, mas a tendência de alta dos preços dos produtos primários se confirmou após meados de 2009, demonstrando que ainda se manterá por um longo período, talvez o ciclo seja de até vinte anos.

Então, o principal desafio dos países latino-americanos, que se beneficiam dessa alta dos produtos primários no comércio internacional, será a disseminação da riqueza gerada nesse setor primário para outras áreas da economia juntamente com a promoção de crescimento econômico sustentável, desenvolvimento tecnológico e diminuição das desigualdades sociais.

A bonança econômica também beneficiou o Chile que, a partir da década de 1970, rompeu, como política de Estado, com a ISI e adotou um modelo de desenvolvimento econômico baseado no setor primário-exportador.

No caso chileno, essa estratégia de desenvolvimento econômico, baseada no uso dos recursos primários, permitiu a geração de renda e riqueza que foram utilizadas em outras áreas da economia, favorecendo o crescimento econômico, sobretudo diante da alta dos preços das commodities no comércio internacional. A literatura econômica já aponta a existência da "bonança do cobre" (GREGORIO, 2006) que beneficiará ainda mais o Chile.

Conjugando essa trajetória de desenvolvimento com políticas econômicas anticíclicas nas áreas monetária, fiscal e cambial, o Chile alcançou um desempenho econômico promissor com rígido controle da inflação e dos gastos públicos, porém, isto não foi suficiente para reduzir os níveis de pobreza, miséria e desigualdades existentes no país, havendo um aprofundamento da exclusão social. O "mercado" sozinho não conseguiu resolver os problemas do "subdesenvolvimento" que foram gestados ao longo de vários séculos nos quais o país foi colônia de exploração espanhola e depois, no século XX, sob a dominação econômica regional dos Estados Unidos.

Isto é um dos principais pontos negativos do modelo de desenvolvimento econômico chileno, mas já estão surgindo propostas (INFANTE E SUNKEL, 2009; GREGORIO, 2006) para a implementação de políticas públicas que promovam o crescimento econômico com equidade. Portanto, o caso chileno sugere que sejam efetivamente adotadas políticas públicas mais ativas para a distribuição dos benefícios oriundos da expansão econômica.

É necessário cautela na análise do caso chileno, pois não se pode abandonar totalmente as teses de Prebisch e de Furtado, desenvolvidas no âmbito da CEPAL, em especial no tocante à teoria histórico-estruturalista que analisou o subdesenvolvimento dos países latino-americanos a partir da relação centro-periferia e da própria história econômica e social da América Latina.

Os fatos ocorridos na história da própria humanidade não podem ser esquecidos e nem apagados. Conforme já apontou Furtado (1970, p. 21, grifo nosso), a partir da Primeira Guerra Mundial, "[...] a América Latina deixou de ser uma expressão geográfica para transformar-se em uma realidade histórica como decorrência do processo de industrialização, iniciado tardiamente, e da forma particular de dependência que se estabeleceu entre os países da região e os Estados Unidos". 
Dessa maneira, a elevação dos preços dos produtos primários no mercado internacional está beneficiando os países latino-americanos de um modo geral, mas é preciso que eles adotem políticas macroeconômicas mais adequadas e utilizem de boa governança para lidar com esse ciclo econômico favorável.

É preciso discutir como os países latino-americanos irão aproveitar a bonança econômica porque esse processo é crucial para o futuro da América Latina. Então, o presente trabalho não exaure os questionamentos em relação ao tema abordado, mas contribui para o enriquecimento dessas discussões tão imprescindíveis na atualidade.

\section{REFERÊNCIAS BIBLIOGRÁFICAS}

BACHA, Edmar L. e FISHLOW, Albert. O ascenso recente nos preços das commodities e o crescimento da américa latina: mais que vinho velho em garrafa nova? (The recent commodity price boom and Latin American growth: more than new bottles for an old wine?). Tradução de Helga Hoffmann, Disponível em: <http://iepecdg.com.br/uploads/texto/111208_commodities_america_latina.pdf> Acesso em: 02. jul. 2012.

BRAGA, Márcio Bobik. Integração econômica na América Latina: uma interpretação das contribuições da CEPAL. Cadernos PROLAM, São Paulo, LTr, ano I, v. 1, n. 1, p. 01-26, 2002.

Raul Prebisch e o livre-comércio: as origens do pensamento econômico estruturalista, Cadernos PROLAM, São Paulo, LTr, ano VII, v. 2, n. 2, p. 77-99, 2008.

BIELSCHOWSKY, Ricardo. Cinquenta anos de pensamento na CEPAL: uma resenha. In: BIELSCHOWSKY, Ricardo (Org.). Cinquenta anos de pensamento na CEPAL, Rio de Janeiro, COFECON/Record, v. 1, p. 13-68, 2000.

Vigência das contribuições de Celso Furtado ao estruturalismo. Revista da CEPAL, número especial em português, p. 183-191, maio 2010.

CEPAL. O regionalismo aberto na América Latina e no Caribe: a integração a serviço da transformação produtiva com equidade. In: BIELSCHOWSKY, Ricardo (Org.). Cinquenta anos de pensamento na CEPAL, Rio de Janeiro, COFECON/Record, v. 2, p. 937-958, 2000.

FfRENCH-DAVIS, Ricardo e MUNOZ, Oscar. As economias latino-americanas (1950-1990). In: BETHELL, Leslie (Org.). A América Latina após 1930, São Paulo, EDUSP, v. VI, p. 129-228, 2009.

FRENKEL, Roberto e RAPETTI, Martín. Fragilidad externa o desindustrialización: ¿Cuál es la principal amenaza para América Latina en la próxima década? Revista da CEPAL, Serie Macroeconomía del Desarrollo, n. 116, p. 03-37, 2011.

FURTADO, Celso. Formação econômica da América Latina. 2. ed. Rio de Janeiro: Lia Editor S.A., 1970. Formação econômica do Brasil. 23. ed. São Paulo: Editora Nacional, 1989.

GREGORIO, José de. Bonanza del cobre: Impacto macroeconómico y desafíos de política. Centro de Estudios Públicos, n. 103, p. 17-42, 2006. Disponível em: <http://www.cepchile.cl/dms/lang_1/ doc_3832.html> Acesso em: 02. jul. 2012.

INFANTE, Ricardo e SUNKEL, Osvaldo. Chile: hacia un desarrollo inclusivo. Revista da CEPAL, n. 97, p. 135-154, abr. 2009.

MILL, Stuart. Princípios de economia política. Coleção "Os Economistas". São Paulo: Abril, 1983.

OCAMPO, José A. A macroeconomia da bonança econômica latino-americana. Revista da CEPAL, número especial em português, p. 77-99, maio 2010. 
PREBISCH, Raúl (a). O desenvolvimento econômico da América Latina e alguns de seus principais problemas. In: BIELSCHOWSKY, Ricardo (Org.). Cinquenta anos de pensamento na CEPAL, Rio de Janeiro, COFECON/Record, v. 1, p. 69-93, 2000.

(b). O mercado comum latino-americano. In: BIELSCHOWSKY, Ricardo (Org.). Cinquenta anos de pensamento na CEPAL, Rio de Janeiro, COFECON/Record, v. 1, p. 347-371, 2000. ROUQUIÉ, Alain. O extremo ocidente: introdução à América Latina. Tradução de Mary Amazonas Leite de Barros. São Paulo: EDUSP, 1991. 